\title{
间歇反应器内醋酸丁酯酯化反应与渗透汽化集成过程的模型计算
}

\author{
邹旳 ${ }^{1}$, 童张法 ${ }^{1}$, 刘 琨 ${ }^{1}$, 冯献社 ${ }^{2}$ \\ 1 广西大学化学化工学院, 广西南宁 530004 \\ 2滑铁卢大学化工系，加拿大安大略省滑铁卢N2L $3 \mathrm{G} 1$
}

\begin{abstract}
摘要: 建立了一个间歇反应器内酯化反应与渗透汽化集成过程的数学模型, 用于描述反应和脱水同时进行的过程. 该模型考虑 了反应体系中所有组分的渗透量影响以及混合物的非理想热力学行为. 选择乙酸和正丁醇生成醋酸丁酯的酯化反应与 PVA 膜 渗透汽化集成过程为研究体系, 将模型结果与文献中已报道的实验数据进行对比, 验证了该模型的有效性. 结果表明,采用渗透 汽化脱除酯化反应的水分将提高酯的产率. 对温度、反应物初始比、膜面积与反应体积比以及催化剂浓度几种操作条件对集成 过程性能影响进行了参数的分析. 根据结果讨论得到该膜过程与反应集成过程的优化操作条件.
\end{abstract}

关键词: 渗透汽化; 酯化反应; 渗透; 集成过程; 集成因子

中图分类号: O643 文献标识码: A

\section{Modeling of Esterification in a Batch Reactor Coupled with Pervaporation for Production of $n$-Butyl Acetate}

\author{
ZOU Yun ${ }^{1}$, TONG Zhangfa ${ }^{1, *}$, LIU Kun ${ }^{1}$, FENG Xianshe ${ }^{2}$ \\ ${ }^{1}$ School of Chemistry and Chemical Engineering, Guangxi University, Nanning 530004, Guangxi, China; \\ ${ }^{2}$ Department of Chemical Engineering, University of Waterloo, Waterloo N2L 3G1, Ontario, Canada
}

\begin{abstract}
A mathematical model for esterification in a batch reactor coupled with pervaporation to describe a simultaneous reaction and water removal from the reactor was developed. The permeation of all components in the reaction mixture and their non-ideal thermodynamic behavior were taken into account. The esterification of acetic acid with $n$-butanol for the production of $n$-butyl acetate integrated with a poly(vinyl alcohol) pervaporation membrane was selected as the model system for this study. The validity of the model was tested by comparing the calculated results with experimental data reported in the literature. The results show that the esterification is facilitated by water removal using pervaporation, which accelerates the rate of ester formation. A parametric study was carried out to evaluate the effects of operating conditions on the performance of the pervaporation-coupled esterification reactor and this included temperature, initial composition of the reactants, membrane area relative to the reactor's size, and catalyst concentration. Based on these results, suitable operating conditions for the membrane-integrated reaction process are discussed.
\end{abstract}

Key words: pervaporation; esterification; permeation; integrated process; coupling factor

Pervaporation is considered to be a potential membrane process that can be coupled with reactions to shift reaction equilibria towards higher product yields by the selective removal of certain product components [1,2]. For example, when esterification is coupled with pervaporation, a complete conversion can be obtained for the integrated process by the removal of water from the reaction mixture [3]. A number of catalytic distillation systems have also been investigated to increase the esterification conversion by cou- pling with pervaporation [4-6].

Mathematical modeling of integrated reaction-membrane processes has attracted great interest because it can provide an insight into the industrial design and optimal operation of these processes. A modeling study on a pervaporation membrane reactor for the esterification of propionic acid and propanol was carried out by David et al. [7]. However, the effects of temperature and variations in feed concentration were not taken into full consideration, and thus this

Received date: 13 April 2010.

*Corresponding author. Tel.: +86-771-3239697; Fax: +86-771-3236634; E-mail: zhftong@sina.com

Foundation item: Supported by the Guangxi Foundation for Returned Overseas Scholars (0575002).

English edition available online at ScienceDirect (http://www.sciencedirect.com/science/journal/18722067). 
model cannot be applied to a broad range of operating conditions. A parametric study of a batch reactor coupled with pervaporation was carried out by Feng et al. [8], and the influence of operating parameters on reactor performance was analyzed. The synthesis of iso-amyl acetate facilitated by pervaporation was reported by $\mathrm{Xu}$ et al. [9] and a parametric regression was conducted based on their experimental data. Krupiczka et al. [10] proposed a three-parameter model to describe the esterification of acetic acid with ethanol coupled with pervaporation and chemical activities instead of concentrations were used in the model so that the true kinetic constants of the reaction could be used for a wide range of component concentrations. A kinetic model describing the esterification-pervaporation hybrid process has also been studied by Li et al. [11], who considered the effects of temperature and concentration of water in the reaction mixtures on the esterification of $n$-butanol with acetic acid. In view of the high selectivity of the hydrophilic membrane for water permeation, an assumption was made that only water was removed from the reaction mixture by the membrane. Using $\mathrm{Zr}\left(\mathrm{SO}_{4}\right)_{2}$ as a catalyst, the esterification of acetic acid with $n$-butanol coupled with pervaporation was studied by Liu et al. [12], who also assumed negligible permeation fluxes of $n$-butanol and $n$-butyl acetate through the membrane. To our knowledge, the non-ideal thermodynamic effects of the quaternary mixtures of water/acetic acid $/ n$-butanol $/ n$-butyl acetate have not been taken into account in modeling studies.

The objective of this work was to develop a mathematical model to more accurately describe the performance of a batch reactor for the esterification of $n$-butyl acetate integrated with pervaporation using a poly(vinyl alcohol) (PVA) membrane. Membrane separation is based on selective permeation through the membrane but no membrane is selective enough to achieve complete separation. Therefore, in this model the permeation fluxes for all four compounds through the membrane were considered based on experimental data available in the literature [13,14]. In addition, the non-ideal thermodynamic effects of the quaternary reaction mixtures were evaluated using the UNIFAC method and the permeation of the components through the membrane upon conversion was investigated. The validity of the model developed here was verified by comparing the model predictions with experimental results available in the literature [12]. Finally, the effects of operating parameters on the esterification performance of the hybrid reaction/pervaporation process were investigated to establish optimal operating conditions.

\section{Theory}

The mathematical model presented here that describes a hybrid system of a batch reactor for esterification coupled with pervaporation is based on three aspects: (a) reaction kinetics of esterification, (b) membrane permselectivity in pervaporation, and (c) mass balance. The following assumptions can be made to simplify the mathematical treatment: (1) constant selectivity of the PVA membrane, (2) isothermal reaction and pervaporation, (3) constant catalyst activity, and (4) the partial molar volume in a mixture is the same as that of a pure component.

\subsection{Model of the membrane reactor}

The stoichiometry of the esterification of acetic acid with $n$-butanol can be represented as

$$
\mathrm{A}+\mathrm{B} \Leftrightarrow \mathrm{E}+\mathrm{W}
$$

where $\mathrm{A}$ is acetic acid, $\mathrm{B}$ is $n$-butanol, $\mathrm{E}$ is the ester, and $\mathrm{W}$ is water. The reaction displays second-order reversible kinetics for a given concentration of catalyst $[15,16]$. Because the stoichiometric coefficients for both reactants and products are the same, the reaction rates expressed with respect to any of the species are numerically equal, differing only in the sign of the rate expressions for the reactants and products. To consider non-ideal thermodynamic behavior of the reaction mixtures, the chemical activities instead of concentrations can be used in the reaction rate equation:

$$
r=k_{1} \gamma_{\mathrm{A}} \gamma_{\mathrm{B}} C_{\mathrm{A}} C_{\mathrm{B}}-k_{2} \gamma_{\mathrm{E}} \gamma_{\mathrm{W}} C_{\mathrm{E}} C_{\mathrm{W}}
$$

where $r$ is the reaction rate $\left(\mathrm{mol} /\left(\mathrm{m}^{3} \cdot \mathrm{h}\right)\right)$ per unit catalyst concentration $C_{\text {cat }}(\mathrm{g} / \mathrm{L})$, and $k_{1}$ and $k_{2}$ are the forward and backward rate constants $\left(\mathrm{m}^{3} /(\mathrm{mol} \cdot \mathrm{h})\right)$, respectively. $C$ is the concentration $\left(\mathrm{mol} / \mathrm{m}^{3}\right)$, and $\gamma$ is and activity coefficient. The concentration is defined as

$$
C_{i}=N_{i} / V
$$

where

$$
V=\sum N_{i} \frac{M_{i}}{\rho_{i}}
$$

$N_{i}$ is the number of moles of component $i$ and $V$ is the volume $\left(\mathrm{m}^{3}\right)$ of the reaction mixture. $M_{\mathrm{i}}$ and $\rho_{\mathrm{i}}$ are the molar mass $(\mathrm{kg} / \mathrm{mol})$ and density $\left(\mathrm{kg} / \mathrm{m}^{3}\right)$ of pure species $i$, respectively. By applying a materials balance, the variation in the number of mole of species $i$ can be expressed as

$$
\frac{\mathrm{d} N_{i}}{\mathrm{~d} t}=-r_{i} V C_{\text {cat }}-J_{i} S
$$

where $J_{i}$ is the permeation flux $\left(\mathrm{mol} /\left(\mathrm{m}^{2} \cdot \mathrm{h}\right)\right)$ of component $i$, and $S$ is the membrane area $\left(\mathrm{m}^{2}\right)$. For the product species, $r_{\mathrm{i}}$ is the rate of formation and has a negative sign. Substituting Eqs. (2) and (3) into Eq. (5), the following relationships can be derived:

$$
\begin{aligned}
\frac{\mathrm{d} N_{\mathrm{A}}}{\mathrm{d} t}= & -\left(k_{1} C_{\mathrm{cat}} \gamma_{\mathrm{A}} \gamma_{\mathrm{B}} N_{\mathrm{A}} N_{\mathrm{B}} / V\right. \\
& \left.-k_{2} C_{\mathrm{cat}} \gamma_{\mathrm{E}} \gamma_{\mathrm{W}} N_{\mathrm{E}} N_{\mathrm{W}} / V\right)-J_{\mathrm{A}} S \\
\frac{\mathrm{d} N_{\mathrm{B}}}{\mathrm{d} t}= & -\left(k_{1} C_{\mathrm{cat}} \gamma_{\mathrm{A}} \gamma_{\mathrm{B}} N_{\mathrm{A}} N_{\mathrm{B}} / V\right. \\
& \left.-k_{2} C_{\mathrm{cat}} \gamma_{\mathrm{E}} \gamma_{\mathrm{W}} N_{\mathrm{E}} N_{\mathrm{W}} / V\right)-J_{\mathrm{B}} S
\end{aligned}
$$




$$
\begin{aligned}
\frac{\mathrm{d} N_{\mathrm{E}}}{\mathrm{d} t}= & \left(k_{1} C_{\mathrm{cat}} \gamma_{\mathrm{A}} \gamma_{\mathrm{B}} N_{\mathrm{A}} N_{\mathrm{B}} / V\right. \\
& \left.-k_{2} C_{\text {cat }} \gamma_{\mathrm{E}} \gamma_{\mathrm{W}} N_{\mathrm{E}} N_{\mathrm{W}} / V\right)-J_{\mathrm{E}} S \\
\frac{\mathrm{d} N_{\mathrm{W}}}{\mathrm{d} t}= & \left(k_{1} C_{\text {cat }} \gamma_{\mathrm{A}} \gamma_{\mathrm{B}} N_{\mathrm{A}} N_{\mathrm{B}} / V\right. \\
& \left.-k_{2} C_{\text {cat }} \gamma_{\mathrm{E}} \gamma_{\mathrm{W}} N_{\mathrm{E}} N_{\mathrm{W}} / V\right)-J_{\mathrm{W}} S
\end{aligned}
$$

The above set of differential equations (i.e., Eqs. (6)-(9)) constitutes the fundamental mathematical model for esterification in a batch reactor coupled with pervaporation.

\subsection{Model of pervaporation}

The permeation flux of pervaporation is generally a function of temperature and concentration. For simplification, we assume that the water/organic selectivity in quaternary mixture through the PVA membrane is equal to the selectivity observed in binary water/organic mixtures. The permeation flux of the organic component can be estimated from the membrane selectivity and water flux. At relatively low water concentrations, the water flux normally exhibits an almost linear relationship to the water concentration and an Arrhenius type relationship to temperature [17],

$$
J_{\mathrm{W}}=\frac{N_{\mathrm{W}}}{V} A_{\mathrm{P}} \exp \left(-\frac{E_{\mathrm{P}}}{R T}\right)
$$

where $E_{\mathrm{P}}$ is the activation energy for water permeation $(\mathrm{kJ} / \mathrm{mol})$ and $A_{\mathrm{P}}$ is the pre-exponential factor $(\mathrm{m} / \mathrm{h})$, which is obtained from experimental pervaporation data. When describing the selectivity of a membrane for the separation of a water/organic binary mixture, the separation factor [2] is defined as

$$
\alpha_{\mathrm{W} i}=\frac{Y_{\mathrm{W}} / Y_{i}}{X_{\mathrm{W}} / X_{i}}
$$

where $\alpha_{\mathrm{W} i}$ is the separation factor for the binary water/organic mixture, and $X$ and $Y$ are the mole fractions in the feed and the permeate, respectively. The subscripts W and $i$ denote the water and organic component $i$, respectively. Because the mole fraction ratio of water to the organic component in the permeate is equal to their flux ratio, the permeation flux of the organic component can be evaluated:

$$
J_{i}=J_{\mathrm{W}} \frac{N_{i}}{\alpha_{\mathrm{W} i} N_{\mathrm{W}}}=\frac{N_{i}}{V} A_{\mathrm{P}} \exp \left(-\frac{E_{\mathrm{P}}}{R T}\right) \frac{1}{\alpha_{\mathrm{W} i}}
$$

Substituting Eq. (10) for the water flux and Eq. (12) for the organic flux into Eqs. (6)-(9), the quantities of reactant and product components in the reaction mixture at a given instant can be determined numerically by solving the differential equations using the Runge-Kutta method [18] once the initial conditions are known.

In a previous study [14], the rate of water removal by pervaporation relative to the rate of water formation by reaction was used to investigate the significance of water re- moval on esterification conversion. In this work, the generalized parameter $F_{i}$ is defined as

$$
F_{i}=\frac{J_{i} S / V}{r_{i}}
$$

where $F_{i}$ is a dimensionless parameter that represents the ratio of the removal rate of species $i$ due to pervaporation to the overall reaction rate. For the reactant species, $F_{i}<0$, indicating the reaction conversion will be negatively affected by the permeation of the reactant through the membrane. For the product species $F_{i}>0$, indicating that the reaction conversion will be enhanced by pervaporative removal of the product components. It is obvious that the use of a water selective PVA membrane will be advantageous to the esterification reaction because of the preferential removal of water from the reaction mixture. The parameter $F$ is a coupling factor and measures how the permeation of one component affects the conversion of the reaction.

\subsection{Validation of the model}

To verify the applicability of the developed model, the esterification catalyzed by $\mathrm{Zr}\left(\mathrm{SO}_{4}\right)_{2} \cdot 4 \mathrm{H}_{2} \mathrm{O}$ and coupled with pervaporation using a PVA membrane was selected as a model system because the relevant data (i.e., membrane permselectivity, kinetic constants of the reaction, and experimental data of pervaporation-facilitated esterification) are available in the literature [13,14]. In their work, the thickness of the active PVA separation layer was ca. $20 \mu \mathrm{m}$. The forward and backward reaction rate constants for the esterification of $n$-butyl acetate catalyzed by $\mathrm{Zr}\left(\mathrm{SO}_{4}\right)_{2} \cdot 4 \mathrm{H}_{2} \mathrm{O}$ are given by

$$
\begin{aligned}
& k_{1}=4.531 \times 10^{6} \exp \left(-\frac{53.13 \times 10^{3}}{R T}\right) \\
& k_{2}=4.376 \times 10^{6} \exp \left(-\frac{58.94 \times 10^{3}}{R T}\right)
\end{aligned}
$$

An Arrhenius type of relationship between temperature and water flux for the water/organic separation is shown in Fig. 1 , and the quantities $E_{\mathrm{P}}$ and $A_{\mathrm{P}}$ for water permeation can be obtained, as shown in Table 1. As a first approximation, the average values of $A_{\mathrm{P}}$ and $E_{\mathrm{P}}$ for the permeation of water in the binary water/organic systems were used to characterize water permeation in the quaternary reaction mixtures.

Excess acetic acid is usually used in the esterification reaction. If $R_{0}$ is the mole ratio of acetic acid to $n$-butanol at the start of the reaction (i.e., $R_{0}=N_{\mathrm{A} 0} / N_{\mathrm{B} 0}$ ) the initial conditions are $N_{\mathrm{A}}=R_{0} N_{\mathrm{B} 0}, N_{\mathrm{B}}=N_{\mathrm{B} 0}, N_{\mathrm{E}}=0$, and $N_{\mathrm{W}}=0$ at $t=0$.

The activity coefficient of each compound is a function of $N_{\mathrm{A}}, N_{\mathrm{B}}, N_{\mathrm{E}}, N_{\mathrm{W}}$ and temperature. In solving the differential equations, all the activity coefficients were calculated using the UNIFAC group contribution method, which is applicable to multicomponent systems when the phase equilibrium 


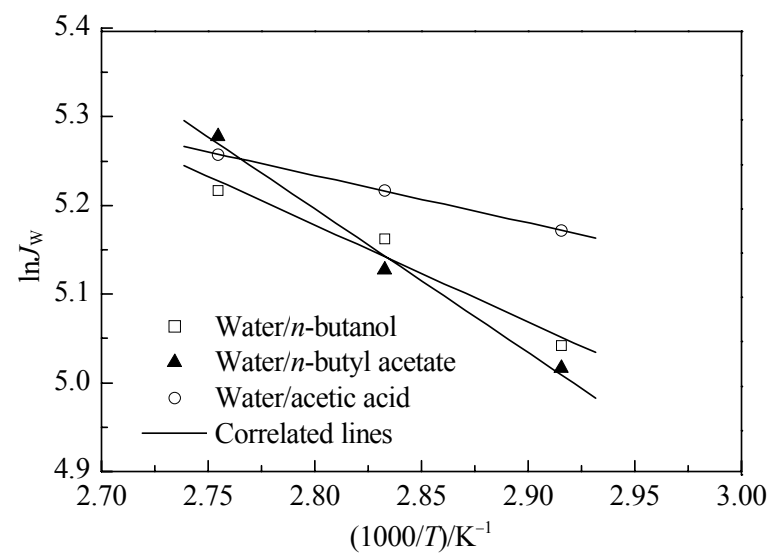

Fig. 1. Temperature dependence of the water flux for the permeation of binary mixtures.

Table 1 Pervaporation of water/organic binary mixtures using the PVA membrane

\begin{tabular}{lccrc}
\hline System & $\alpha_{\mathrm{W} i}$ & $\begin{array}{c}J_{\mathrm{W}} / \\
\left(\mathrm{g} /\left(\mathrm{m}^{2} \cdot \mathrm{h}\right)\right)\end{array}$ & $\begin{array}{c}E_{\mathrm{P}} / \\
(\mathrm{kJ} / \mathrm{mol})\end{array}$ & $\begin{array}{c}A_{\mathrm{P}} / \\
(\mathrm{m} / \mathrm{h})\end{array}$ \\
\hline Water $n$-butanol & $12.2-16.5$ & $154-184$ & 9.10 & 0.830 \\
Water $n$-butyl acetate & $432-441$ & $150-196$ & 13.48 & 3.665 \\
Water/acetic acid & $9.0-10.8$ & $176-192$ & 4.45 & 0.145 \\
\hline
\end{tabular}

data is not available [19]. The volume, surface, and interaction parameters of the groups relevant to the quaternary mixtures studied here are shown in Table 2.

The experimental data and model calculations for the conversion are shown in Fig. 2 where the dotted line repre-

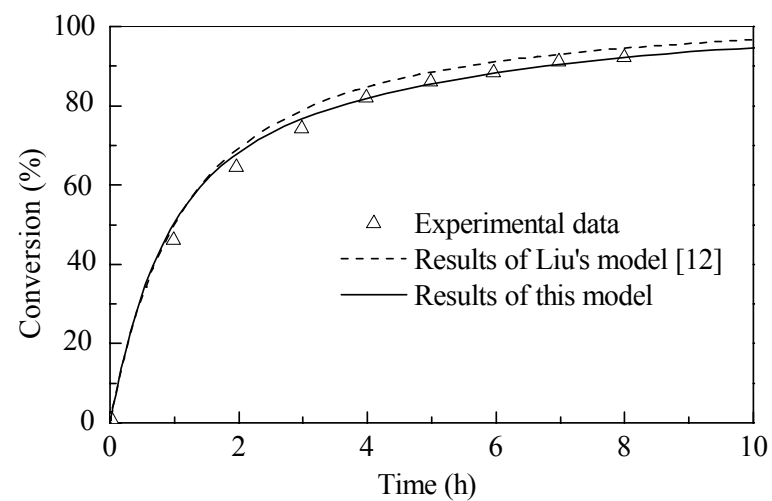

Fig. 2. Conversion versus time: a comparison of model calculations with experimental data. Operating conditions: $T=353 \mathrm{~K}, R_{0}=1.6$, $S / V_{0}=23 \mathrm{~m}^{-1}, C_{\text {cat }}=10.6 \mathrm{~g} / \mathrm{L} . S / V_{0}$ : membrane area per unit volume of the reactor; $C_{\text {cat }}$ : catalyst concentration. sents the calculated results based on the model of Liu et al. [12]. The solid line represents the calculations based on our work. Both models appear to agree well with the experimental data. However, the reaction conversion is slightly overestimated by the Liu's model [12] because the permeation fluxes of $n$-butanol and $n$-butyl acetate were neglected and the non-ideal thermodynamic behavior of the reaction mixtures was not considered in their work.

Figure 3 shows the total permeation flux and the partial fluxes of water, acetic acid, $n$-butanol, and $n$-butyl acetate through the membrane during the course of the reaction. The model predictions agree with the experimental data. Water is clearly the dominant component in the total flux because of the high selectivity of the PVA membrane for water.

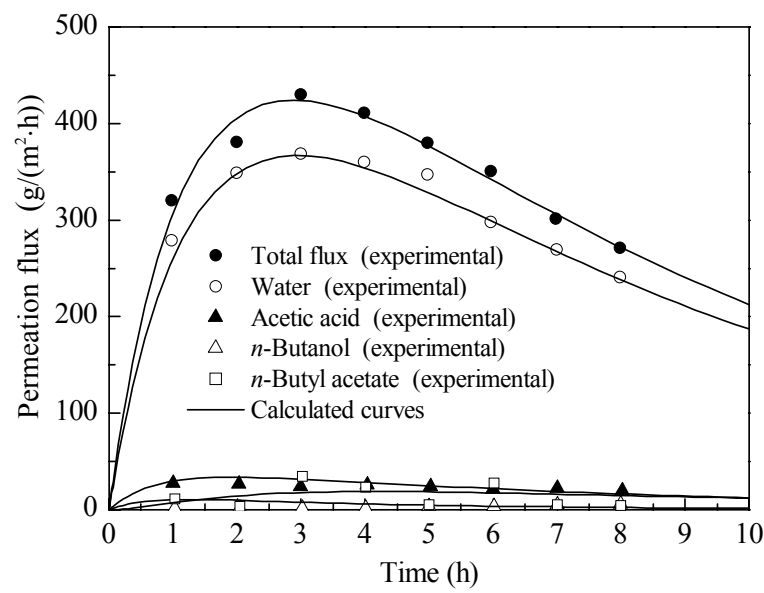

Fig. 3. Variations in permeation flux through the membrane with time. Operating conditions: $T=353 \mathrm{~K}, R_{0}=1.6, S / V_{0}=23 \mathrm{~m}^{-1}, C_{\text {cat }}=$ $10.6 \mathrm{~g} / \mathrm{L}$.

Variations in the activity coefficients with time are shown in Fig. 4, which illustrates the non-ideal thermodynamic behavior of the quaternary mixtures. The activity coefficient for $n$-butyl acetate is much greater than unity because of its strong interaction with the other components in the mixture. The activity coefficient of water gradually approaches unity as the water content in the mixture decreases with time.

The coupling factors $F_{i}$ of individual components as a function of time are plotted in Fig. 5. $F_{\mathrm{W}}$ increases rapidly with time during the first three hours and then decreases slowly. On the other hand, the coupling factors for acetic

Table 2 UNIFAC parameters for the four compounds in the mixture

\begin{tabular}{ccccccccc}
\hline Group & $\mathrm{CH}_{3}$ & $\mathrm{CH}_{2}$ & $\mathrm{COOH}$ & $\mathrm{COOC}$ & $\mathrm{CCOH}$ & $\mathrm{H}_{2} \mathrm{O}$ & $R_{\mathrm{k}}$ & $Q_{\mathrm{k}}$ \\
\hline $\mathrm{CH}_{3}$ & 0 & 0 & 663.50 & 232.10 & 737.5 & 1318 & 0.9011 & 0.8480 \\
$\mathrm{CH}_{2}$ & 0 & 0 & 663.50 & 231.10 & 737.5 & 1318 & 0.6744 & 0.5400 \\
$\mathrm{COOH}$ & 315.30 & 315.30 & 0 & -256.3 & -17.59 & -292.0 & 1.3013 & 1.2240 \\
$\mathrm{COOC}$ & 114.80 & 114.80 & 660.20 & 0 & 109.9 & 1135 & 1.9031 & 1.7280 \\
$\mathrm{CCOH}$ & -87.93 & -87.93 & 77.61 & 76.20 & 0 & 285.4 & 1.8788 & 1.6640 \\
$\mathrm{H}_{2} \mathrm{O}$ & 580.60 & 580.60 & 225.40 & -455.40 & -148.5 & 0 & 0.9200 & 1.4000 \\
\hline
\end{tabular}




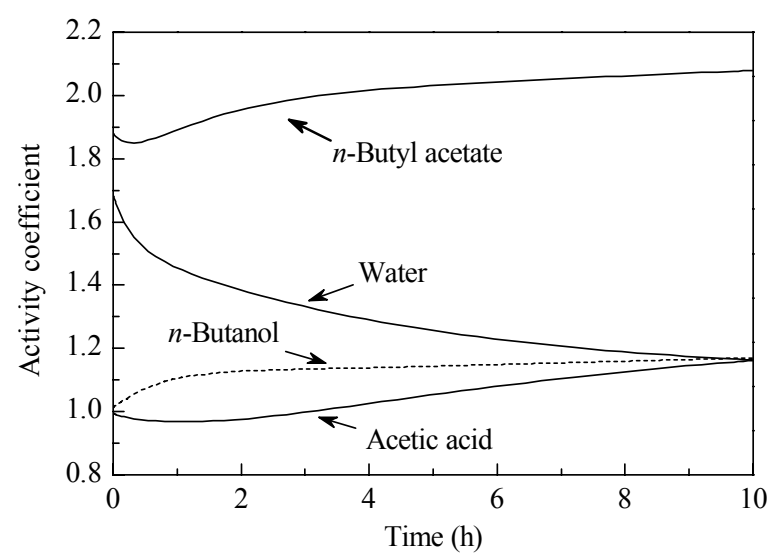

Fig. 4. Activity coefficients of the components in the reaction mixture calculated using the UNIFAC model. Operating conditions: $T=$ $353 \mathrm{~K}, R_{0}=1.6, S / V_{0}=23 \mathrm{~m}^{-1}, C_{\text {cat }}=10.6 \mathrm{~g} / \mathrm{L}$.

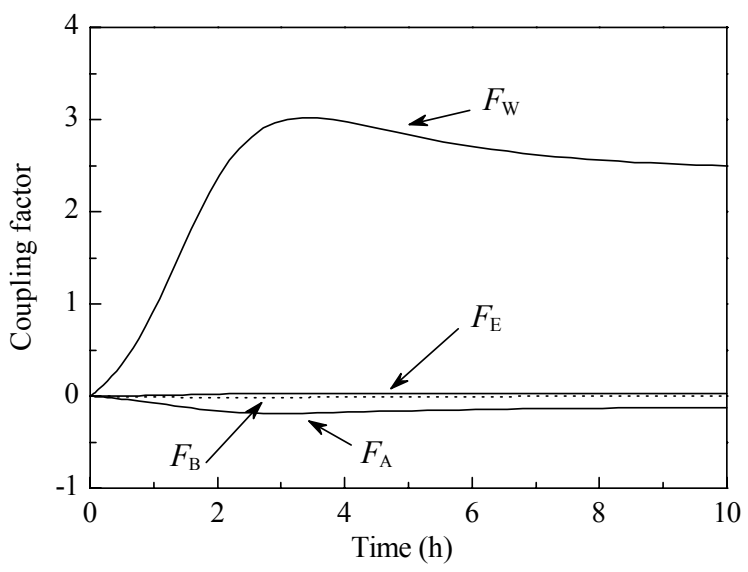

Fig. 5. Pervaporation/reaction coupling factor for individual components in the pervaporation-coupled reactor. Operating conditions: $T=$ $353 \mathrm{~K}, R_{0}=1.6, S / V_{0}=23 \mathrm{~m}^{-1}, C_{\text {cat }}=10.6 \mathrm{~g} / \mathrm{L}$.

acid, $n$-butanol, and $n$-butyl acetate are much smaller than $F_{\mathrm{W}}$ because of the high selectivity of the hydrophilic PVA membrane for water permeation. The permeation of acetic acid and $n$-butanol negatively affects the esterification. However, because their permeation fluxes through the membrane are very low, $F_{\mathrm{A}}$ and $F_{\mathrm{B}}$ are not too far below zero, indicating that the slow permeation of these two components through the membrane does not affect the esterification conversion significantly.

\section{Parametric analysis}

Two parameters $P$ and $Q$ defined in Eqs. (16) and (17) can be used to measure the performance of the batch reactor integrated with pervaporation:

$$
\begin{gathered}
P=\frac{N_{\mathrm{E}}}{N_{\mathrm{B} 0}} \\
Q=\frac{N_{\mathrm{W}}}{N_{\mathrm{B} 0}}
\end{gathered}
$$

where $P$ is a measure of the fractional conversion of the feed butanol for ester production and $Q$ is a measure of the water quantity in the mixture. $P$ and $Q$ are equal for esterification in a stand-alone batch reactor without pervaporation. The difference $(P-Q)$ measures the water removal rate by the membrane's relative water formation rate in the reaction. The influence of the four major operating parameters involved in the integrated process on esterification performance were investigated and these include $T, R_{0}, S / V_{0}$, and $C_{\text {cat }}$.

Figure 6 shows the calculated values for $P$ and $Q$ at different temperatures at $S / V_{0}=23 \mathrm{~m}^{-1}, C_{\text {cat }}=10.6 \mathrm{~g} / \mathrm{L}$, and $R_{0}$ $=1.6$. An increase in the temperature enhances the esterification reaction because a higher temperature favors both water removal by pervaporation and the rate of reaction. A maximum quantity of water exists in the reactor during the course of the reaction. This is because as reaction proceeds with time, more water is formed and at the same time, the rate of water removal by the membrane also increases because of the increased driving force for water permeation. During the early stage of the reaction, the water formed in the reactor is not immediately removed resulting in water accumulating in the reactor. However, at a sufficiently high water concentration, water removal becomes faster than water formation leading to water depletion in the reactor. At higher temperatures, the "maximum" water content in the reactor is higher than at lower temperatures and this maximum appears quicker as well because an increase in temperature increases both the permeation and reaction rates. However, the reaction is exothermic and increasing temperature will be less advantageous as far as the reaction equilibrium is concerned. The calculation results in Fig. 6 show that at temperatures above $353 \mathrm{~K}$, a further increase in temperature will not increase the reaction conversion significantly. Therefore, considering the operating costs asso-

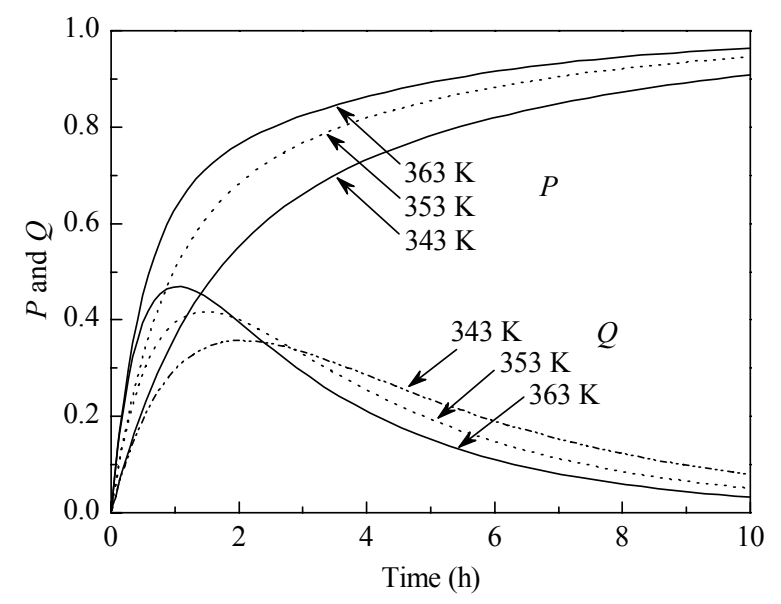

Fig. 6. Effect of temperature on the esterification performance of the pervaporation-coupled reactor. Operating conditions: $R_{0}=1.6, S / V_{0}=$ $23 \mathrm{~m}^{-1}, C_{\text {cat }}=10.6 \mathrm{~g} / \mathrm{L}$. 
ciated with heating and cooling of reaction mixtures, a moderate temperature of around $353 \mathrm{~K}$ appears appropriate for esterification coupled with pervaporation.

Figure 7 shows the effect of initial mole ratio of acetic acid to $n$-butanol, $R_{0}$, on the performance of the pervaporation-coupled reactor for esterification under the following conditions: $S / V_{0}=23 \mathrm{~m}^{-1}, C_{\text {cat }}=10.6 \mathrm{~g} / \mathrm{L}$, and $T=353 \mathrm{~K}$. The extent of esterification increases with an increase in $R_{0}$. At the same time, increasing $R_{0}$ also leads to a higher yield of water in the reactor because water formation is enhanced with the use of an excess amount of reactant. The water permeation flux decreases because of the relatively low water concentration at a higher $R_{0}$. However, if the initial ratio $R_{0}$ is sufficiently high, subsequent extraction of the ester product from the reaction mixture will be challenging because of the relatively large amount of acetic acid present in the reactor. A moderate value of $R_{0}$ (e.g., 1.5) is considered appropriate by considering the tradeoff relationship between the reaction yield and the ease of product recovery.

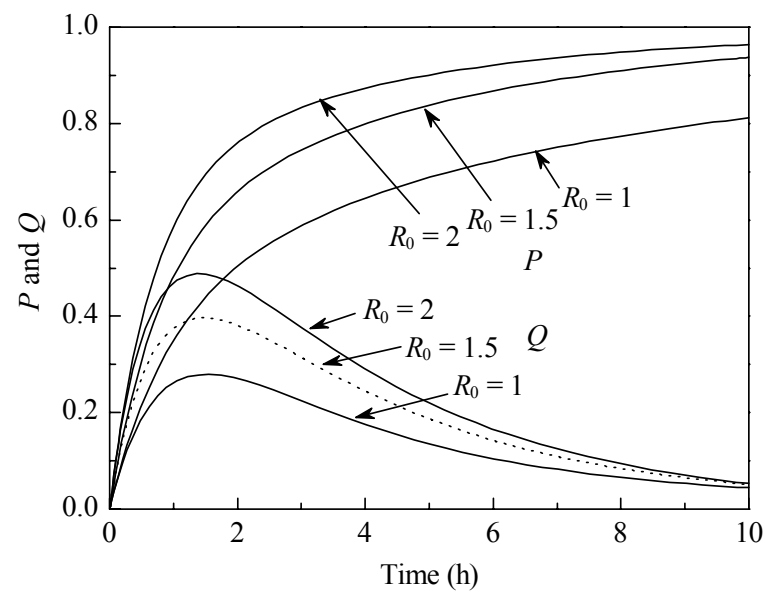

Fig. 7. Effect of excess reactant (acetic acid) on the esterification performance of the pervaporation-coupled reactor. Operating conditions: $S / V_{0}=23 \mathrm{~m}^{-1}, C_{\text {cat }}=10.6 \mathrm{~g} / \mathrm{L}, T=353 \mathrm{~K}$.

Figure 8 illustrates the effect of $S / V_{0}$ on the esterification performance in the pervaporation-coupled reactor under the following conditions: $R_{0}=1.6, C_{\text {cat }}=10.6 \mathrm{~g} / \mathrm{L}$, and $T=353$ K. An increase in $S / V_{0}$ increases the value of $P$ and decreases the value of $Q$. For a given reactor volume, increasing the membrane area will increase the rate of water removal and the reaction equilibrium will shift toward the product side. In addition, because water is continuously removed as soon as it is formed, the reactant concentration will increase resulting in an increase in the reaction rate. However, an increase in the membrane area represents an increase in the capital cost of the pervaporation unit.

Figure 9 shows the reaction conversion over an operating time of $10 \mathrm{~h}$ at different $S / V_{0}$ values. No significant improvement in the conversion is obtained when $S / V_{0}$ is over

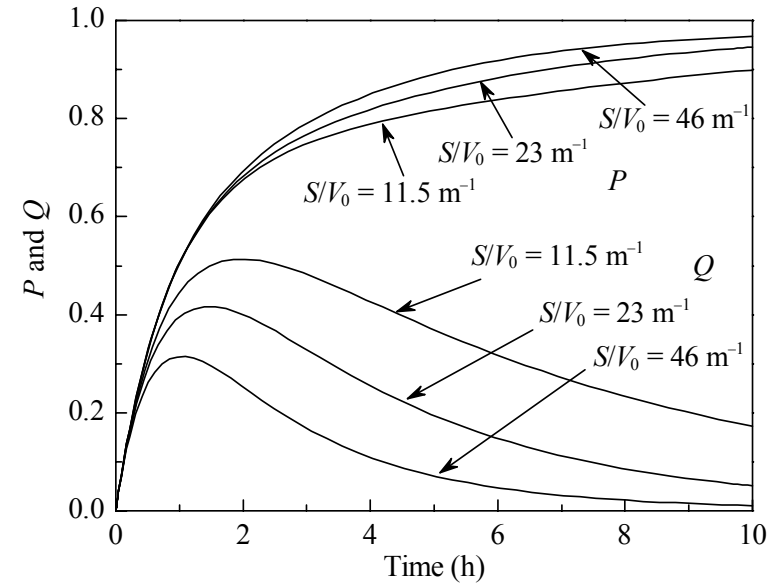

Fig. 8. Effect of $\left(S / V_{0}\right)$ on the esterification performance of the pervaporation-coupled reactor. $R_{0}=1.6, C_{\text {cat }}=10.6 \mathrm{~g} / \mathrm{L}, T=353 \mathrm{~K}$.

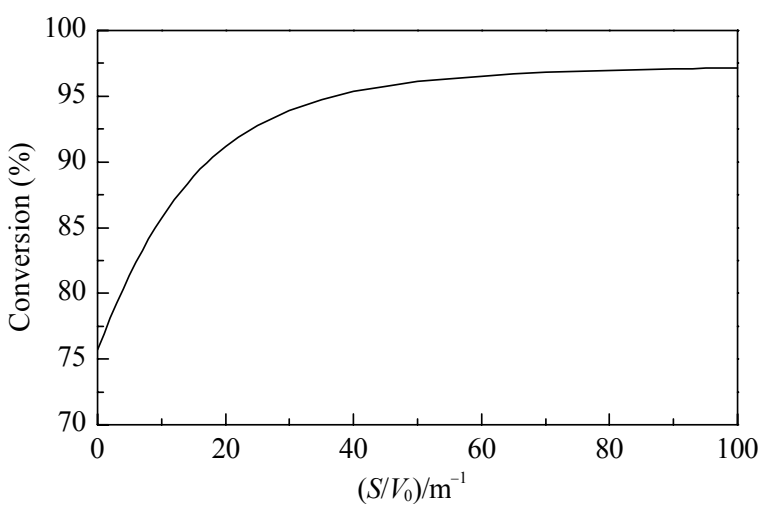

Fig. 9. Reaction conversion at $t=10 \mathrm{~h}$ for different values of $S / V_{0}$. Other conditions: $T=353 \mathrm{~K}, R_{0}=1.6, C_{\text {cat }}=10.6 \mathrm{~g} / \mathrm{L}$.

$30 \mathrm{~m}^{-1}$ and obviously, the gain in the enhanced conversion versus the cost associated with the membrane should be considered when determining the appropriate value of $S / V_{0}$.

Figure 10 shows the effect of catalyst concentration on the esterification performance of the pervaporation-coupled

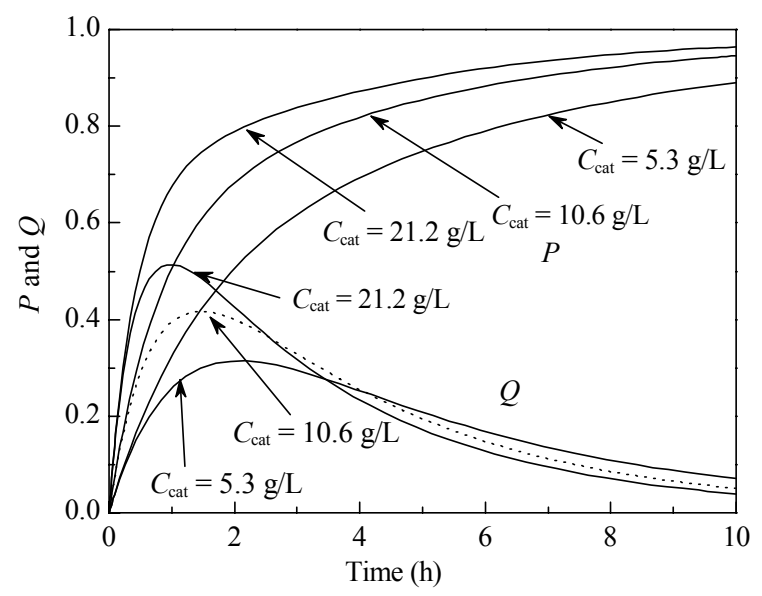

Fig. 10. Effect of catalyst concentration on the esterification performance of the pervaporation-coupled reactor. Operating conditions: $S / V_{0}=23 \mathrm{~m}^{-1}, R_{0}=1.6, T=353 \mathrm{~K}$. 
reactor under the following conditions: $S / V_{0}=23 \mathrm{~m}^{-1}, R_{0}=$ 1.6, and $T=353 \mathrm{~K}$. As expected, increasing the catalyst concentration promotes the formation of $n$-butyl acetate and also of water in the reactor. Since the rate of water removal increases with an increase in the reactor water content a maximum $Q$ exists during the reaction and it occurs within the first $2 \mathrm{~h}$ of the reaction. As noted previously [14], there is little change in the product yield when the catalyst concentration is above $20 \mathrm{~g} / \mathrm{L}$ for a reaction time of $10 \mathrm{~h}$ under the conditions studied. This should be taken into account when selecting a suitable catalyst concentration.

\section{Conclusions}

A mathematical model of esterification in a batch reactor integrated with pervaporation was developed by taking into account the non-ideal thermodynamic behavior of the reaction mixtures. The enhanced performance of the hybrid process is attributed to the continuous removal of water by pervaporation during the course of reaction. The model is validated with experimental data from the literature. A parametric analysis was carried out to evaluate the effects of process parameters on esterification conversion. Based on model calculations, the following operating conditions were shown to be appropriate for the esterification of acetic acid and butanol for the production of butyl acetate: temperature $\sim 353 \mathrm{~K}$, catalyst concentration $20 \mathrm{~g} / \mathrm{L}, S / V_{0} 30 \mathrm{~m}^{-1}$, excess amount of acetic acid relative to butanol $50 \%$.

\section{Nomenclature}

$A_{\mathrm{P}} \quad$ pre-exponential factor $(\mathrm{m} / \mathrm{h})$

$C$ concentration $\left(\mathrm{mol} / \mathrm{m}^{3}\right)$

$N \quad$ chemical quantity (mol)

$N_{0} \quad$ initial quantity (mol)

$E_{\mathrm{P}} \quad$ activation energy for pervaporation $(\mathrm{kJ} / \mathrm{mol})$

$F \quad$ coupling factor (dimensionless)

$J$ permeation flux $\left(\mathrm{mol} /\left(\mathrm{m}^{2} \cdot \mathrm{h}\right)\right)$

$k_{1}$ rate constant of the forward esterification reaction $\left(\mathrm{m}^{3} /(\mathrm{mol} \cdot \mathrm{h})\right)$

$k_{2}$ reaction rate constant of the reverse esterification reaction $\left(\mathrm{m}^{3} /(\mathrm{mol} \cdot \mathrm{h})\right)$

$M \quad$ molar mass $(\mathrm{kg} / \mathrm{mol})$

$R \quad$ universal gas constant $(8.314 \mathrm{~J} /(\mathrm{mol} \cdot \mathrm{K}))$

$R_{0}$ ratio of the initial moles of acetic acid to moles of $n$-butanol

$S \quad$ membrane area $\left(\mathrm{m}^{2}\right)$

$T$ temperature $(\mathrm{K})$

$t$ time (h)

$V_{0} \quad$ initial volume of reaction mixture $\left(\mathrm{m}^{3}\right)$
$V \quad$ volume of reaction mixture $\left(\mathrm{m}^{3}\right)$

$C_{\text {cat }}$ catalyst concentration $(\mathrm{g} / \mathrm{L})$

$\rho \quad$ density $\left(\mathrm{kg} / \mathrm{m}^{3}\right)$

$\alpha_{\mathrm{W} i}$ separation factor of water/organic binary mixtures (dimensionless)

$\gamma \quad$ activity coefficient (dimensionless)

\section{Subscripts}

$\begin{array}{ll}\text { A } & \text { acetic acid } \\ \text { B } & n \text {-butanol } \\ \text { E } & n \text {-butyl acetate ester } \\ i & \text { component } i \text { in the reaction mixture } \\ \text { W } & \text { water }\end{array}$

\section{Acknowledgments}

The authors express their appreciation to Dr. Donald G. Barnes, Visiting Professor of Chemistry at Guangxi University, for helpful discussions and comments during the preparation of this manuscript. We would like to thank the editors for inviting this contribution to the journal in celebration of its 30th anniversary.

\section{References}

1 Lipnizki F, Field R W, Ten P K. J Membr Sci, 1999, 153: 183

2 Feng X S, Huang R Y M. Ind Eng Chem Res, 1997, 36: 1048

3 Liu K, Feng X, Tong Z F, Liu L. Sep Sci Technol, 2005, 40: 2021

4 Liao A P, Tong Z F. Chem React Eng, Technol, 1995, 11: 406

5 Yan J M, Chen G W. Membr Sci Technol, 2002, 22(5): 6

6 Liu K, Tong Z F, Liu L, Feng X S. J Membr Sci, 2005, 256: 193

7 David M O, Gref R, Nguyen T Q, Neel J. Chem Eng Res Design, 1991, 69(A): 335

8 Feng X S, Huang R Y M. Chem Eng Sci, 1996, 51: 4673

9 Xu Z L, Qu R, Shi Y J, Yu J L. Membr Sci Technol, 1996, 16(2): 58

10 Krupiczka R, Koszorz Z. Sep Purif Technol, 1999, 16: 55

11 Li X H, Wang L. J Membr Sci, 2001, 186: 19

12 Liu Q L, Chen H F. J Membr Sci, 2002, 196: 171

13 Zhu Y S, Chen H F. J Membr Sci, 1998, 138: 123

14 Liu Q L, Zhang Z B, Chen H F. J Membr Sci, 2001, 182: 173

15 Grob S, Hasse H. Ind Eng Chem Res, 2006, 45: 1869

16 Sanz M T, Gmehling J. Chem Eng J, 2006, 123: 9

17 Feng X S, Huang R Y M. J Membr Sci, 1996, 118: 127

18 Qi R H, Henson M A. Comput Chem Eng, 2000, 24: 2719

19 Fredenslund A, Jones R L, Prausnitz J M. AIChE J, 1975, 21: 1086 